\title{
Empirical Study on Coupling and Coordinated Development of "Energy-Finance-Environment" in the Middle Reaches of Yangtze River
}

\author{
Duyun Peng ${ }^{1, *}$ \\ ${ }^{1}$ School of Statistics, Jiangxi University of Finance and Economics, Nanchang 330010, China
}

\begin{abstract}
In the important transition period of high-quality development in China, it is of great significance to explore the coordinated development among finance, energy and environment. In this paper, the dynamic average weight method with improved entropy value is used, and the index system of "energy-finance-environment" three-dimensional system (hereinafter referred to as "EFE system") is established to explore the coordinated development and dynamic evolution of the coupling. The results show that the newly constructed dynamic average weighting method is reasonable and effective, and can reflect the time-varying characteristics of each subsystem index weight; from 2009 to 2017, the EFE values of the four provinces in the middle reaches of the Yangtze river present different development trends, and the trend of finance shows an overall upward trend, while the trend of environment and energy show twists and turns; the coupling degrees of the four provinces are high, but the coordination degrees are generally low, failing to reach the coordination level; the restricting factors of coordinated development are mainly the backward type of financial development and energy efficiency. This conclusion provides a reference for a more rational grasp of the coordinated development of EFE system in the middle reaches of Yangtze river.
\end{abstract}

\section{Introduction}

Environment is the basis and premise of human society, energy is the strategic resource of social and economic development, and finance is the core of modern economy. As the important three areas of today's economic society, the three affect each other and are closely connected. In today's economic globalization and financialization, extensive economic development mode has brought huge hidden dangers to the society, and the mutual influence among the three is increasingly evident. In this context, many challenges require provinces in the middle reaches of the Yangtze river to solve the relationship between energy, finance and environment, and achieve coordinated development of the three.

Many scholars at home and abroad have explored the relationship between energy, finance and environment. $\mathrm{H}$. qualitatively analyzes the correlation mechanism between energy and finance[1]. Wang et al. analyzed the relationship between China's financial structure and energy structure, concluded that financial correlation ratio has a positive effect on energy structure, while financial savings structure has a negative effect on energy structure[2]. However, coupling coordination model is mostly used to explore the relationship between systems. Coupling is a physics concept, which refers to the phenomenon that two or more systems affect each other and even move together through interaction. Related scholars have qualitatively or quantitatively discussed the coordinated development of economy, environment, energy and other systems, and obtain satisfactory results[3-5]. At abroad, Kon. made correlation analysis of economy and environment under uncertain information[6]. In China, Li Yang studied the coupling coordination degree of regional economy, tourism industry and ecological environment from the perspective of low carbon, and concluded that economy, tourism and ecological environment are mutually dependent[7]. The correlation mechanism between EFE has attracted more and more attention from scholars. However, whether the goal of coordinated development can be achieved according to the previous development trajectory are still to be evaluated scientifically. Moreover, some economic phenomena will change with time, and the specific influencing factors are also complex. Therefore, in this paper, by referring to relevant literature, the dynamic average weight method of improved entropy value is used for reference. Compared with the existing weighting method, the dynamic average weighting method makes the weight more close to the original change law of time series data, reflects the timing characteristics of indicators, and expands the research and application of dynamic weighting method.

To sum up, based on previous studies, this paper takes the four provinces and regions in the middle reaches of the Yangtze river as examples to explore how to coordinate energy, finance and environment to ensure

\footnotetext{
*Corresponding author: ukyo1823@163.com
} 
sustainable development. This paper firstly constructs EFE system evaluation system, then uses improved dynamic average empowerment method of entropy, measures the coupling coordination degree between the EFE system based on the coefficient model of capacitive coupling in physics and analyzes the relationship between energy, finance and environment. The results provide a reference value for rational understanding of the four provinces and cities in the middle reaches of the Yangtze river and working out more scientific and effective EFE policies in the future.

\section{Construction of index system and evaluation methods}

\subsection{Constructing the EFE index system}

On the basis of literature researches, this paper selects 15 indexes that can reflect the characteristics of EFE according to the principles of high occurrence frequency, easy availability of data, comparability[8-10]. And the index data needed in this paper comes from "Statistical Yearbook" and "Provincial Urban Construction Statistical Yearbook" of Anhui, Hubei, Hunan and Jiangxi provinces involved in the middle reaches of the Yangtze river from 2009 to 2017.

Table 1. EFE index system

\begin{tabular}{|c|c|c|}
\hline Target layer & Criterion layer & Index layer \\
\hline \multirow{5}{*}{$\begin{array}{c}\text { Energy System } \\
\mathrm{X}\end{array}$} & \multirow{3}{*}{$\begin{array}{l}\text { Energy capacity } \\
\qquad \mathrm{X}_{1}\end{array}$} & Total energy production $\left(10,000\right.$ tons of SCE) $\quad \mathrm{x}_{11}$ \\
\hline & & Total energy consumption $\left(10,000\right.$ tons of SCE) $\mathrm{x}_{12}$ \\
\hline & & Investment of the energy industry (100 million yuan) \\
\hline & \multirow{2}{*}{$\begin{array}{c}\text { Energy structure } \\
\mathrm{X}_{2}\end{array}$} & Elasticity ratio of energy consumption $\mathrm{X}_{21}$ \\
\hline & & Energy intensity by GDP (tce/10,000yuan) $\mathrm{x}_{22}$ \\
\hline \multirow{5}{*}{$\begin{array}{c}\text { Financial System } \\
\text { Y }\end{array}$} & \multirow{2}{*}{$\begin{array}{c}\text { Financial scale } \\
\mathrm{Y}_{1} \\
\end{array}$} & Deposit balance of financial institution (100 million yuan) \\
\hline & & Premium of primary insurance (100 million yuan) $\quad \mathrm{y}_{12}$ \\
\hline & \multirow{3}{*}{$\begin{array}{l}\text { Financial efficiency } \\
\qquad \mathrm{Y}_{2}\end{array}$} & Financial interrelations ratio (\%) $\mathrm{y}_{21}$ \\
\hline & & Insurance density (yuan/person) $\quad$ y22 \\
\hline & & Deposit-loan ratio of financial institution (\%) \\
\hline \multirow{5}{*}{$\begin{array}{l}\text { Environmental } \\
\text { System } \\
\text { Z }\end{array}$} & \multirow{2}{*}{$\begin{array}{c}\text { Environmental protection } \\
\mathrm{Z}_{1} \\
\end{array}$} & Treatment rate of consumption Wastes (\%) $\mathrm{z}_{11}$ \\
\hline & & Daily urban sewage treatment capacity $\left(10,000 \mathrm{~m}^{3}\right) \quad \mathrm{Z} 12$ \\
\hline & \multirow{3}{*}{$\begin{array}{c}\text { Ambient level } \\
\mathrm{Z}_{2}\end{array}$} & Urban park green space per capita (sq.m/person) $\mathrm{z}_{21}$ \\
\hline & & Green coverage rate of built district (\%) $\mathrm{Z}_{22}$ \\
\hline & & Area of nature reserve $(10,000$ hectares $) \quad \mathrm{Z}_{23}$ \\
\hline
\end{tabular}

\subsection{Establishment evaluating model}

\subsubsection{Determination of dynamic index weight}

Scholars often use entropy method for objective weight of indicators. However, considering the actual situation, the importance degree of the same indicator will be different in different development stages of the region, and the entropy method fails to fully consider the interference of time difference on the importance degree of the indicator. The dynamic average weighting method adopted in this paper can make up for this deficiency, and the weight calculated by it can better reflect the time series variation rules and characteristics of the index[11].

(1)Selecting the initial time $\left[\mathrm{t}_{1}, \mathrm{t}_{\mathrm{a}}\right]$ and calculating the correlation coefficient between the $\mathrm{j}_{\text {th }}$ index and other indicators $r_{\mathrm{jk}}(\mathrm{k}=1,2, \cdots, \mathrm{m})$ by using the original data in this area;

(2)The complex correlation coefficient is used to modify the entropy value to obtain the moment entropy value $e_{j}$ and initial weight $\omega_{j}$ of the $j_{\text {th }}$ index;

$$
e_{j}=\left(\sum_{j=1}^{m} \mid r_{j k}\right) \times \frac{-1}{\ln n} \sum_{i=1}^{n} \frac{x_{i j}}{\sum_{i=1}^{n} x_{i j}} \ln \left(\frac{x_{i j}}{\sum_{i=1}^{\mathrm{n}} x_{i j}}\right) \quad \omega_{j}=\frac{1-e_{j}}{m-\sum_{i=1}^{\mathrm{m}} e_{i}}
$$

(3)Selecting time interval $\left[t_{2}, t_{a+1}\right], \ldots,\left[t_{n-a+1}, t_{n}\right]$ to repeat steps (1) and (2) until entropy value and initial weight at all times are obtained;

(4)Substituting the moment entropy value and initial weight calculated in (3) into the following formula to calculate the required moment weight $\mathrm{w}_{t_{k}}$;

$$
\mathrm{w}_{t_{k}}=\left\{\begin{array}{l}
\frac{1}{k} \sum_{i=1}^{k} w_{i}, \quad k=1,2, \ldots, \quad a-1 \\
\frac{1}{a} \sum_{i=k}^{p+k-1} w_{i}, \quad k=a, \quad a+1, \ldots, \quad n-a+1 \\
\frac{1}{\mathrm{n}-k+1} \sum_{i=k}^{n} w_{i}, \quad k=n-a+2, \quad n-a+3, \ldots, \quad n
\end{array}\right.
$$

The comprehensive evaluation function.

$$
U_{\mathrm{j}}=\sum_{i=1}^{n} x_{i j}^{\prime} \mathrm{w}_{j}
$$

$U_{\mathrm{j}}$ is the comprehensive evaluation value; ${ }^{\mathrm{x}_{i j}}$ represents the value of the $j_{\text {th }}$ evaluation index in the $i_{\text {th }}$ year.

\subsubsection{Coupling harmonious degree model}

The phenomenon that two or more systems affect each other is called coupling. The coupling degree model of EFE system is, 


$$
C_{3}=\sqrt[3]{\frac{U_{1} * U_{2} * U_{3}}{\left(\frac{U_{1}+U_{2}+U_{3}}{3}\right)^{3}}}
$$

Among them, $\mathrm{U}_{1}, \mathrm{U}_{2}$ and $\mathrm{U}_{3}$ are the comprehensive evaluation indexes of energy system, financial system and environmental system respectively, and $\mathrm{C}_{3}$ represents the coupling degree of EFE system. Coupling degree value $0<\mathrm{C}<1$. When $\mathrm{C}=1$, the coupling degree is the maximum, and the benign coupling between systems is achieved. When $\mathrm{C}=0$, the coupling degree is minimal and the systems are in independent states[12-13].

$$
\begin{aligned}
& T=\sqrt[3]{\alpha U_{1} * \beta U_{2} * \gamma U_{3}} \\
& D=\sqrt{C^{*} T}
\end{aligned}
$$

$\mathrm{C}$ is the degree of coupling; $\mathrm{T}$ is the comprehensive coordination index of EFE system; D is coupling coordination degree; $\alpha, \beta$ and $\gamma$ are undetermined coefficients, $\quad \alpha=\beta=\gamma=\frac{1}{3}$.

\section{Determine the evaluation index grade and the weights}

\subsection{Determine the index value of the evaluation index grade}

By referring to relevant literature[12-14], this paper divides the results of the development of coupling coordination into 10 grades. Through the results, we can directly see the current level of the development of coupling coordination in each province.

Table 2. Coordination degree grade classification standard.

\begin{tabular}{|c|c|c|c|}
\hline $\begin{array}{c}\text { Coupling } \\
\text { compatibility }\end{array}$ & $\begin{array}{c}\text { Coordination } \\
\text { level }\end{array}$ & $\begin{array}{c}\text { Coupling } \\
\text { compatibility }\end{array}$ & $\begin{array}{c}\text { Coordination } \\
\text { level }\end{array}$ \\
\hline $0.00-0.09$ & $\begin{array}{c}\text { Extreme } \\
\text { disorder }\end{array}$ & $0.50-0.59$ & $\begin{array}{c}\text { Reluctantly } \\
\text { coordinated }\end{array}$ \\
\hline $0.10-0.19$ & $\begin{array}{c}\text { Seriously } \\
\text { disorder }\end{array}$ & $0.60-0.69$ & $\begin{array}{c}\text { Primary } \\
\text { coordination }\end{array}$ \\
\hline $0.20-0.29$ & $\begin{array}{c}\text { Moderate } \\
\text { Maladjustment }\end{array}$ & $0.70-0.79$ & $\begin{array}{c}\text { moderately } \\
\text { coordinated }\end{array}$ \\
\hline $0.30-0.39$ & $\begin{array}{c}\text { Mild } \\
\text { Maladjustment }\end{array}$ & $0.80-0.89$ & $\begin{array}{c}\text { Good } \\
\text { coordination }\end{array}$ \\
\hline $0.40-0.49$ & $\begin{array}{c}\text { On the Verge } \\
\text { of Imbalance }\end{array}$ & $0.90-1.00$ & Well-coordinated \\
\hline
\end{tabular}

\subsection{Determine the index value of the evaluation index grade}

Since the time span of the data is from 2009 to 2017, the selected time interval is [2009, 2013], [2010,2014]..., [2013,2017]. It can be known that the weight of each index changes with the time, indicating that the influence degree of this index on each corresponding evaluation object in different years is constantly changing, which fully reflects the dynamic characteristics of the weight and the rationality of the newly constructed dynamic average weighting method based on improved entropy value in this paper. In different regions, the weight of the same index will be different due to different geographical environment, government policies and industrial structure. The dynamic average weighting model of improved entropy value constructed in this paper is scientific and reasonable to determine the dynamic weight of indicators, and can better restore the development law of economic phenomena.

Table 3. Index weight.

\begin{tabular}{|c|c|c|c|c|c|c|}
\hline Province & Variable & Mean & Variable & Mean & Variable & Mean \\
\hline \multirow{5}{*}{ Anhui } & $x_{11}$ & 0.1776 & $y_{11}$ & 0.2088 & $Z_{11}$ & 0.2153 \\
\cline { 2 - 7 } & $x_{12}$ & 0.2201 & $y_{12}$ & 0.2116 & $Z_{12}$ & 0.1753 \\
\cline { 2 - 7 } & $x_{13}$ & 0.1894 & $y_{21}$ & 0.1893 & $Z_{21}$ & 0.2224 \\
\cline { 2 - 7 } & $x_{21}$ & 0.2292 & $y_{22}$ & 0.2075 & $Z_{22}$ & 0.2237 \\
\cline { 2 - 7 } & $x_{22}$ & 0.1797 & $y_{23}$ & 0.1828 & $Z_{23}$ & 0.1633 \\
\hline \multirow{5}{*}{ Hubei } & $x_{11}$ & 0.1406 & $y_{11}$ & 0.2104 & $Z_{11}$ & 0.2292 \\
\cline { 2 - 7 } & $x_{12}$ & 0.1855 & $y_{12}$ & 0.2086 & $Z_{12}$ & 0.2251 \\
\cline { 2 - 7 } & $x_{13}$ & 0.2225 & $y_{21}$ & 0.1913 & $Z_{21}$ & 0.1968 \\
\cline { 2 - 7 } & $x_{21}$ & 0.2647 & $y_{22}$ & 0.1998 & $Z_{22}$ & 0.1310 \\
\cline { 2 - 7 } & $x_{22}$ & 0.1867 & $y_{23}$ & 0.1899 & $Z_{23}$ & 0.2177 \\
\hline \multirow{5}{*}{ Hunan } & $x_{11}$ & 0.2173 & $y_{11}$ & 0.2305 & $Z_{11}$ & 0.2208 \\
\cline { 2 - 7 } & $x_{12}$ & 0.1946 & $y_{12}$ & 0.2376 & $Z_{12}$ & 0.1305 \\
\cline { 2 - 7 } & $x_{13}$ & 0.1788 & $y_{21}$ & 0.1845 & $Z_{21}$ & 0.2229 \\
\cline { 2 - 7 } & $x_{21}$ & 0.2276 & $y_{22}$ & 0.2297 & $Z_{22}$ & 0.2293 \\
\cline { 2 - 7 } & $x_{22}$ & 0.1816 & $y_{23}$ & 0.1176 & $Z_{23}$ & 0.1965 \\
\hline & $x_{11}$ & 0.2006 & $y_{11}$ & 0.2070 & $Z_{11}$ & 0.2364 \\
\cline { 2 - 7 } & $x_{12}$ & 0.2354 & $y_{12}$ & 0.2029 & $Z_{12}$ & 0.2061 \\
\cline { 2 - 7 } & $x_{13}$ & 0.2166 & $y_{21}$ & 0.2028 & $Z_{21}$ & 0.2019 \\
\cline { 2 - 5 } & $x_{21}$ & 0.2447 & $y_{22}$ & 0.2076 & $Z_{22}$ & 0.1614 \\
\cline { 2 - 6 } & $x_{22}$ & 0.1027 & $y_{23}$ & 0.1798 & $Z_{23}$ & 0.1942 \\
\hline
\end{tabular}

\section{The measurement and the analysis}

\subsection{Calculation of coupling compatibility}

Firstly, the comprehensive evaluation model and the improved entropy method are used to determine the weight model to calculate the comprehensive scores of EFE systems. There are some spatial differences among provinces with different dominant subsystems. From the perspective of the energy subsystem, the energy assessment values of the four provinces and regions tend to vary greatly and have poor development stability, among which Anhui and Hunan have frequent fluctuations, while Jiangxi maintains a low state. The financial evaluation values of the four provinces show a steady upward trend, and from the environmental subsystem, the values of Hunan and Jiangxi have fluctuated somewhat in recent years.

\subsection{Result and analysis of the coupling degree and coupling coordination degree}

Secondly, this paper uses the evaluation values to measure the coupling degree and coupling coordination degree. 


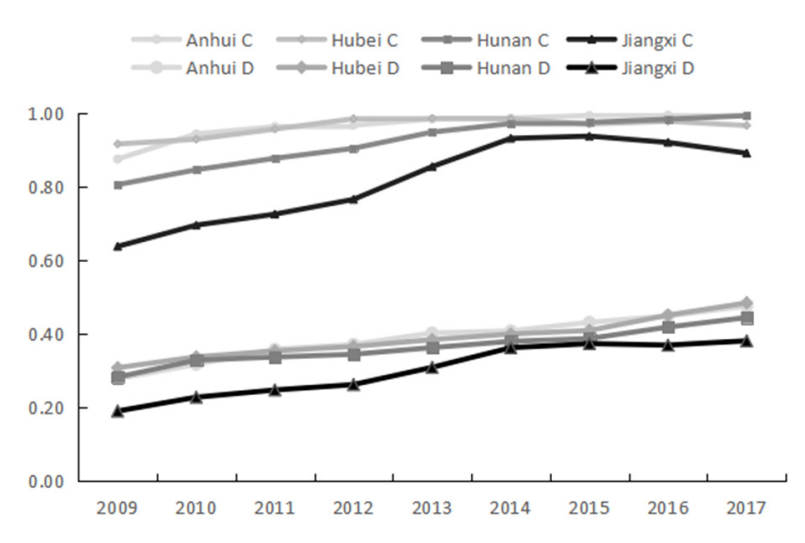

Fig. 1. Time series changes from 2009 to 2017

Notice: $\mathrm{C}$ is the coupling degree, and $\mathrm{D}$ is the coupling coordination degree.

From the perspective of coupling degree, the EFE system from 2009 to 2017 is generally in the stage of high coupling. This indicates that EFE are strongly correlated, and the four provinces can protect the environment while developing economy and finance. In 2009, there are some differences in coupling degree in 4 provinces. This difference continues until 2014, and the coupling degree of each province increases in this range, indicating that the correlation degree between EFE systems gradually increased. From 2014 to 2017, the coupling degree of the four provinces are basically stable at above 0.9 .

In terms of coordination degree, the overall trend of EFE system in the past 9 years is mainly steady rise. But the degree of coordination is not reaching the level of "well-coordinated",basically in "Mild Maladjustment" and "Moderate Maladjustment" stage. In recent years, provinces have followed the "rise of the central region" strategy, given full play to their resource advantages and geographical advantages, focused on the construction of ecological civilization, promoted the stable development of energy finance, and strengthened financial innovation, all which provide important supports for the development of energy finance and ecological environment governance. Therefore, the coordinated development level of energy, finance and environment EFE system has been increased to some extent.
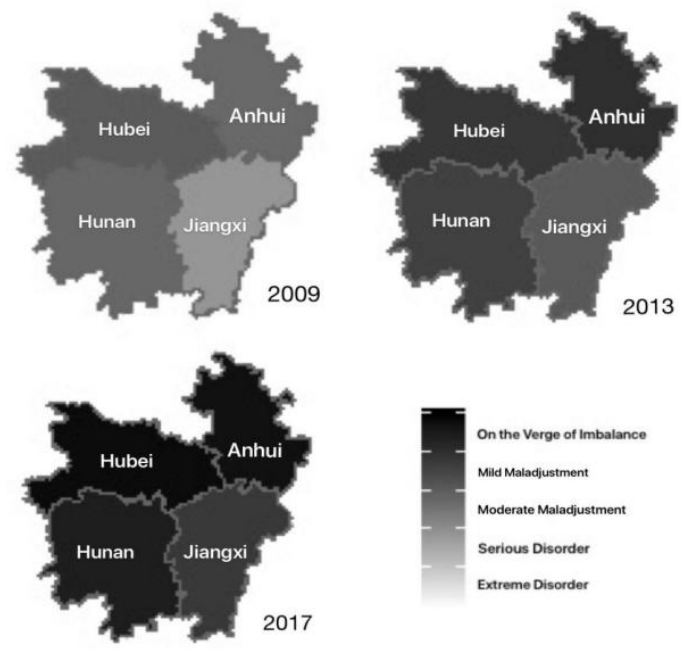

Fig. 2. Coordination evolution in 2009, 2013 and 2017

With the help of ggplot package in the R software, the schematic diagram of EFE system coordination evolution in 2009, 2013 and 2017 in 4 provinces are made. It can be seen that Hubei is always in the leading position of the four provinces. Second, Anhui and Hunan go up for three grades, Jiangxi energy finance develops slowly. Under the support of a series of policies, Jiangxi insists on promoting the development of energy finance and ecological environment in a coordinated way, and steadily promotes the coordinated development of EFE system. In general, from 2009 to 2013 to 2017, the coordination degree of the four provinces maintain an upward trend, but the coordination degree is relatively low, and none of them crosses the level of the verge of imbalance. Therefore, each province still needs to take corresponding measures to steadily improve the coordination level of EFE system.

Table 4. Coordination level

\begin{tabular}{|c|c|c|c|c|c|c|c|}
\hline & $\mathrm{U} 1$ & $\mathrm{U} 2$ & $\mathrm{U} 3$ & $\mathrm{C}$ & $\mathrm{D}$ & $\begin{array}{c}\text { Coordination } \\
\text { level }\end{array}$ & $\begin{array}{c}\text { Major } \\
\text { constraint }\end{array}$ \\
\hline Anhui & 0.5215 & 0.4244 & 0.5145 & 0.9658 & 0.3876 & $\begin{array}{c}\text { Mild } \\
\text { Maladjustment }\end{array}$ & $\begin{array}{c}\text { financial } \\
\text { development } \\
\text { backward }\end{array}$ \\
\hline Hubei & 0.4820 & 0.4694 & 0.5264 & 0.9628 & 0.3878 & $\begin{array}{c}\text { Mild } \\
\text { Maladjustment }\end{array}$ & $\begin{array}{c}\text { financial } \\
\text { development } \\
\text { backward }\end{array}$ \\
\hline Hunan & 0.5622 & 0.3161 & 0.5265 & 0.9221 & 0.3648 & $\begin{array}{c}\text { Mild } \\
\text { Maladjustment }\end{array}$ & $\begin{array}{c}\text { financial } \\
\text { development } \\
\text { backward }\end{array}$ \\
\hline Jiangxi & 0.2635 & 0.2764 & 0.6753 & 0.8171 & 0.3024 & $\begin{array}{c}\text { Mild } \\
\text { Maladjustment }\end{array}$ & $\begin{array}{c}\text { energy } \\
\text { efficiency } \\
\text { backward }\end{array}$ \\
\hline
\end{tabular}

By calculating and sorting out the mean value of subsystem evaluation and coupling coordination degree of the four provinces, it is found that the factors restricting the coupling coordination development of the four provinces are basically the lagging financial development, including Anhui, Hubei and Hunan, indicating that the financial development of the three provinces and regions still needs to be further developed. Only Jiangxi province shows energy efficiency backward type, indicating that although Jiangxi province 
is rich in energy. There is still some room for improvement in energy efficiency, and its energy efficiency is worth further exploration. To conclude, It can be seen that the EFE systems in the four provinces and regions have not well achieved synchronous development, and to some extent, the development of each other is mutually contained. Therefore, in the future development, each province should start from its own constraints, actively explore effective ways to promote synchronous development, and promote the coordinated development and overall progress of EFE system in the middle Yangtze river region.

\section{Conclusions}

By constructing the EFE system evaluation index system, this paper analyzes the coupling and coordinated development of EFE systems in 4 provinces in the middle reaches of the Yangtze river from 2009 to 2017 by adopting the improved entropy value dynamic average weighting method and coupling coordination model. The following conclusions are drawn.

(1)Using the improved entropy dynamic weight model to measure the EFE system evaluation value, we find that the dominant subsystems of each province are different. During the study period, the trend of finance has been on the rise, while the trend of environment and energy has been in twists and turns. All four provinces are rich in energy, and the economy has been developing rapidly in the price of environment in recent years. Therefore, the four provinces should pay attention to the effective utilization of natural resources and the protection of ecological environment while developing financial economy, and finally form an environment-friendly and green financial development mode.

(2)From the evaluation results of coupling values, it can be seen intuitively that EFE systems have strong correlation and are in the stage of high coupling in the 4 provinces. Whereas, the four provinces started with different coupling degrees in 2009 and achieved certain growth in the coupling degrees from 2009 to 2014, which indicates that the development prospect of EFE system in these six years is relatively optimistic in the 6-year period. In particular, the coupling degree of Jiangxi province increased greatly from 0.64 in 2009 to 0.93 in 2014, indicating that a series of financial development and environmental protection policies of Jiangxi province have achieved certain results. In recent years, the coupling degree of 4 provinces is basically stable, and there is no great room for improvement. The four provinces should break through the weak links according to the constraints of their coordinated development. For example, Jiangxi province should make use of its advantages of large output of agriculture and labor force, strengthen financial innovation and improve energy utilization efficiency to promote coordinated development.

(3)According to the coordination degree and its spatio-temporal dynamic evolution process, the overall disorder of the four provinces is from moderate to mild, and then close to reluctantly coordinated, presenting a steady upward trend. The coordination degree of EFE system is in a good development trend in recent years. The measures to build ecological model in the middle reaches of the Yangtze river have some inspiration for the future development direction. Development is the first priority, and the scientific concept of development with overall consideration reminds us that development is never a single element of development, but a joint development of multiple indicators. Development itself will inevitably cause some energy losses. How to minimize the loss rate should be the focus of future government and scholars.

\section{References}

1. L. He, Research on several theoretical and practical issues of energy finance,Beijing: Science Press(2014).

2. B. Wang,F. Li, K. Wang.Research on the relationship between financial structure and energy structure, Journal of $\mathrm{Xi}$ 'an Jiaotong University: Social Science Edition,34(2014).

3. L. Zhou, L. Che, D. Sun.The coupling and coordinated development of urbanization and economic growth in China and its influencing factors,Economic Geography,06,97-107(2019).

4. C. Liu, D. Duan, R. Yu,et al.Spatial-temporal structure of coupling of the ERE system in Wuhan metropolitan area,China Population, Resources and Environment,24,145-152(2014).

5. C. Fang, J. Cheng, P. Zhao. Spatial-temporal evolution of MEE coupling coordination degree in the Yangtze river economic belt under the great protection strategy, China Population Resources and Environment,29,65-73(2019).

6. K.,Nij.Environmental-economic modeling with semantic insufficiency and factual uncertainty, Environmental System,25,167-183 (1996).

7. Y. Li, F. Wei. Research on the coordination degree of coupling between regional economy, tourism industry and ecological environment from the perspective of low carbon-taking Beijing for example, Shaanxi Agriculture and Forestry Science, 5,199-202(2012).

8. G. Yan. Study on the coupling coordination degree of financial development and economic growth in the Yellow River delta region,Northern Economy, 10,77-80(2018).

9. H. Li, Y. Yuan, N. Wang. Evaluation on the coordinated development of regional green finance and ecological environment coupling,Statistics \& Decision,08,161-164(2019).

10. W. Cai, Y. Xia, X. Zhao. "Ecological environment-economic development-urbanization" coupling coordinated development and forecast analysis in five provinces and regions in northwest China,Chinese Journal of Agricultural Resources and Regional planning,(2019). 
11. P. Yi, Y. Zhou, Y. Guo, W. Li.A dynamic comprehensive evaluation method reflecting the development trend. Operations Research and Management Science,06,175-180(2016).

12. F. Zeng, D. Ye. Analysis of coupling coordination between financial system and industrial structure based on new structural economics perspective.Economic Review, 3,134-147(2017).

13. L. Jiang, L. Bo, Y. Wu. Analysis on the coordination of economy, resources and environment in China's provinces - on the coupling formula of three systems and its extended form.Journal of Natural Resources, 32,5,788-799(2017)

14. S. Wang, L. Tong, Y. He. Quantitative measurement of the coupling relationship between industrial structure and ecological environment in Beijing, Tianjin and Hebei. Soft Science, 33,03,75-79(2019). 